\title{
The Examination of the Contest Performance Results of the Gymnasts Modern Dance Education Which is Applied to the Rhythmic Gymnasts in the Category of Junior
}

\author{
Melis Koca \\ Faculty of Sports Sciences, Akdeniz University, Antalya, Turkey \\ Tel: 90-542-655-5645Ｅ-mail: m.koca650@gmail.com
}

\begin{abstract}
Yunus Emre Bağış (Corresponding author)
Faculty of Sports Sciences, Süleyman Demirel University, Isparta, Turkey

Tel: 90-506-824-2322 E-mail: yunusbagis@sdu.edu.tr
\end{abstract}

Received: April 8, 2020 Accepted: May 14, 2020 Published: May 27, 2020

doi:10.5296/jei.v6i1.16809 URL: https://doi.org/10.5296/jei.v6i1.16809

\begin{abstract}
The purpose of the study is to investigate if there is a difference between the performance results of the gymnasts receiving and not receiving modern dance education, which is applied to the rhythmic gymnasts in the category of junior. The experimental group included 10 rhythmic gymnasts competing in the category of junior in Antalyaspor Club with a mean age of $8.50 \pm 1$, a mean height of $1.16 \pm 0.4$, and a mean weight of 22.7 \pm 3.3 . The Control Group consisted of 10 rhythmic gymnasts competing in the category of junior in Antalyaspor Club with a mean age of $8.10 \pm 1.2$, mean height of $1.19 \pm 0.3$, and with a mean weight of $21.8 \pm 2.4$. Before the study, the gymnasts and their parents were informed about the aim, title and content of the study, and they were also asked for permission. The participants in this study consisted of 20 licensed rhythmic gymnasts competing in the category of junior in Antalyaspor Club. The gymnasts were divided into two groups: Experimental Group and Control Group. All of the modern dance education applied to 10 gymnasts in the Experimental Group was given in Rhythmic Gym Gymnastics School in Antalya city center. The modern dance education was regularly given by a professional choreograph an hour twice a week, in a total of 10 weeks, 20 days and 20 hours. The arithmetic average and the
\end{abstract}


descriptive statistics of all the data found as a result of the measurements were calculated, and the statistical analysis of the data was made using Independent T-Test in SPSS, and a $p$-value $<0.05$ was considered to be significant. According to the findings, it has been found that modern dance education has a positive effect on the contest results. To sum up, it has been concluded that there is a statistically positive and significant correlation between the success of rhythmic gymnasts receiving and not receiving modern dance education. It has been proved that the performance success of the rhythmic gymnasts receiving modern dance education has been increasing. Thus, including modern dance education in rhythmic gymnastics training is thought to affect the gymnasts' success positively.

Keywords: Rhythmic gymnastics, Modern dance, Performance

\section{Introduction}

Rhythmic gymnastics is an Olympic sport in which the participants compete either individually or as a group, and music, dance, gestures, and mimics are used and aesthetics is applied at the highest level. The Rhythmic Gymnastics, which is applied together with acting, ballet and music pantomime, is a branch that is practiced only by women (Morpa Sports Encyclopedia, 1997). Rhythmic Gymnastics requires coordination of various hand tools (rope, ball, circle, pin, ribbon) as well as motoric features that are specific to the branch (Ayça et al., 2008). It is very important in Rhythmic Gymnastics that music, tools and body movements are presented with an artistic and original approach and in aesthetic integrity. One of the factors for success in this difficult sport is mastery in technical field. However, the ability to show a number of compositions in which risky and original movements are involved at the desired performance requires a high level of development of motoric features and a certain physical structure (Agopyan, 1993). Starting gymnastics should be at younger ages than the other sports branches. Here, the main purpose is to give a basic training by highlighting the aesthetic and flexible appearance of the body (Koç, 1996). rhythmic Gymnastics has developed since 1945 mainly on the basis of the movements and principles of classical dance of artistic gymnastics in Eastern Europe (Mathews, 1978).

Questions about what dancing is are usually answered by what the dance means, what meanings it has, and what it symbolically refers to (Galioğlu, 2007). Dancing can be briefly defined as "an art branch in which movement is the tool for feeling, understanding and communicating" (Lin, 2005). Modern dance, is the kind of dance that developed in early $20^{\text {th }}$ Century as a kind of reaction to the constant rules of classical ballet (Narl1, 2014). Although classical ballet has been an art form fascinating people with its visuality for centuries, modern dance emerged as a dance that described the ancient Egyptian and Greek cultures in the last century. The reason for this reaction to classical ballet was economic, technological and scientific developments as well as oppressive and destructive conditions caused by the phenomenon of war on people. This reality surrounding people must be considered not only through reason, but also through intuition, and artists should be free to think, imagine, and create their art. Modern dance is organic, and gives movements a more vital character (Mihcioğlu, 2000).

Today's people wait to see things clearly. The purpose of modern dance is to create new 
perspectives for these distinct formations. However, modern dance is not only based on the idea of expressing specific formations, or shapes, but can express many elements of ballet and music with the body. The movements and gestures develop a new body language, and undertakes the narrative load of the words performing this expression more powerfully. Techniques, skills and aesthetic elements are very important to perform well in dancing. Movements shown in rhythmic gymnastics must be exhibited in harmony with music by combining the elements of emotion, dance, mimic and aesthetics.

The purpose of this study was to examine whether there is a difference in performance results of the rhythmic gymnasts who compete in junior category and who receive modern dance training compared to the rhythmic gymnasts who do not receive this training.

\section{Method}

\subsection{Participants}

The Study Group consisted of 10 rhythmic gymnasts who competed in the junior category at Antalyaspor Club Association who had a mean age of $8.50 \pm 1.0$, a mean body height of $1.16 \pm 0.4$, and a mean body weight of $22.7 \pm 3.3$. The Control Group consisted of 10 rhythmic gymnasts who competed in the junior category at Antalyaspor Club Association with a mean age of $8.10 \pm 1.2$, a mean body height of $1.19 \pm 0.3$, and a mean body weight of $21.8 \pm 2.4$. The study was conducted in line with the Helsinki Declaration and the signed consent forms were obtained from the participants. Before the study was commenced, the athletes and their families were informed about the purpose, subject and contents of the present study, and their permissions were obtained.

\subsection{Height Measurements}

The heights of the athletes were measured by a wall scale. The measurements were made in a barefoot and upright position facing the back on the wall scale while the athletes were in anatomical position on a flat surface. The values were recorded in $\mathrm{cm}$.

\subsection{Body Weight Measurements}

Fakir Hausgerate/Hercules brand electronic scales were used to measure the body weights. The athletes were measured with bare feet and with light sportswear on. The values were recorded in $\mathrm{kg}$.

\subsection{Modern Dance Training}

The Study Group consisted of 20 licensed rhythmic gymnasts competing in the junior category at Antalyaspor Club Association. The gymnasts were divided into two groups as 10 participants in the Study Group, and 10 participants in the Control Group. All of the modern dance training applied to 10 rhythmic gymnasts who were in the Study Group was conducted at the Rhythmic Gym Gymnastics School in Antalya city center. The modern dance training was carried out regularly by a professional choreographer for 10 weeks, 20 days and 20 hours, 2 days each, 2 days per week. The trainings started 11 weeks before the competition, and was completed one week before the competition. 


\subsection{Characteristics of the Competition Series}

All the athletes who participated in the study competed in junior A and B categories. The athletes who competed in the Junior A category were those who were born in 2010-2009-2008, and those who competed in the Junior B category were those who were born in 2013-2012-2011. Only the free series of all the competing athletes were taken into evaluations. The maximum duration of the series was 1.30 minutes. In each category, there were actions that were mandatory and non-mandatory to perform within the series. In case none of these movements were in the series, deductions of 0.30 points were made for each movement.

\subsection{Competition Procedure}

The 2018-2019 Academic Year, School Sports Rhythmic Gymnastics Provincial First Prize Competition was organized at Suleyman Evcilmen Sports and Exhibition Hall in Muratpaşa Municipality in the central district of Antalya. A total of 145 athletes participated to the $1^{\text {st }}$ competition, which was held between 3-5 April 2019. There were 88 athletes in the junior B category; on the $2^{\text {nd }}$ day, there were 57 athletes in the junior A category. In addition to the schools in Antalya city center, athletes coming from the schools in Manavgat and Alanya also participated in the competition.

The athletes who competed in the Junior B category competed only through free series, and those in the Junior A category competed in the free series and ball tool. The individual athletes who made the top 6 were rewarded with medals. The scores of the athletes in the Category A were sorted by collecting their scores in the free series and ball tool.

\subsection{Analysis of the Data}

The arithmetic means and descriptive statistics of all the data that were obtained as a result of the measurements were calculated. The statistical analyses of the data were examined with the Independent $t$-Test in the SPSS Package Program, and the significance level was considered $\mathrm{p}<0.05$. 


\section{1) Macrothink}

\section{Results}

When Table 1 is evaluated, it is seen that the mean age of the Study Group was $8.50 \pm 1.0$ years, the mean height was $1.16 \pm 0.4 \mathrm{~cm}$, and the mean body weight was $22.7 \pm 3.3 \mathrm{~kg}$. The mean age of the Control Group was $8.10 \pm 1.2$ years, the mean height was $1.19 \pm 0.3 \mathrm{~cm}$, and the mean body weight was $21.8 \pm 2.4 \mathrm{~kg}$.

Table 1. Physical characteristics of the athletes

\begin{tabular}{|l|l|l|l|l|}
\hline Group & Parameters (n-20) & Mean.SD & Min. & Max. \\
\hline \multirow{2}{*}{ Study Group } & \multirow{2}{*}{ Age (year) } & $8.50 \pm 1.0$ & 7.0 & 10 \\
\cline { 3 - 5 } Control Group & & $8.10 \pm 1.2$ & 7.0 & 10 \\
\hline Study Group & \multirow{2}{*}{ Height $(\mathrm{cm})$} & $1.16 \pm 0.4$ & 1.12 & 1.25 \\
\cline { 3 - 5 } Control Group & & $1.19 \pm 0.3$ & 1.13 & 1.25 \\
\hline Study Group & \multirow{2}{*}{ Body Weight $(\mathrm{kg})$} & $22.7 \pm 3.3$ & 18.0 & 27.0 \\
\cline { 3 - 5 } Control Group & & $21.8 \pm 2.4$ & 19.0 & 26.0 \\
\hline
\end{tabular}

When Table 2 is evaluated, there was a significant difference between the D scores of the Study Group that were trained with modern dance and the Control Group that did not receive modern dance training $(\mathrm{p}<0.05)$.

Table 2. The D scores of the athletes

\begin{tabular}{|l|l|l|l|l|}
\hline Group & Parameter (n-20) & Mean.SD & t & p \\
\cline { 1 - 4 } Study Group & \multirow{2}{*}{ D score } & $3.50 \pm 3.1$ & \multirow{2}{*}{6.348} & \multirow{2}{*000*}{} \\
\cline { 1 - 1 } Control Group & & $1.89 \pm 7.3$ & & \\
\hline
\end{tabular}

Note. ${ }^{*} \mathrm{p}<0.05$.

In Table 3, it is seen that there was a significant difference between the Study Group that was trained with modern dance and the Control Group that did not receive modern dance training in terms of the E scores $(p<0.05)$. 
Table 3. The E scores of the athletes

\begin{tabular}{|c|c|c|c|c|}
\hline Group & Parameter (n-20) & Mean.SD & $\mathbf{t}$ & $\mathbf{p}$ \\
\hline Study Group & \multirow{2}{*}{ E score } & $5.60 \pm 1.5$ & \multirow{2}{*}{3.382} & \multirow{2}{*}{$.003 *$} \\
\hline Control Group & & $3.43 \pm 1.3$ & & \\
\hline
\end{tabular}

Note. ${ }^{*} \mathrm{p}<0.05$.

When Table 4 is evaluated, it is seen that there was a significant difference between the total scores of the Study Group that were trained with modern dance and the Control Group that did not receive modern dance training $(\mathrm{p}<0.05)$.

Table 4. Total scores of the athletes

\begin{tabular}{|c|c|c|c|c|}
\hline Group & Parameter (n-20) & Mean.SD & $\mathbf{t}$ & $\mathbf{p}$ \\
\hline Study Group & \multirow{2}{*}{ Total score } & $9.10 \pm 1.6$ & \multirow{2}{*}{4.825} & \multirow{2}{*}{$.000 *$} \\
\hline Control Group & & $5.29 \pm 1.8$ & & \\
\hline
\end{tabular}

Note. $* \mathrm{p}<0.05$.

\section{Discussion}

This study was conducted to examine whether performance outcomes of rhythmic gymnasts who compete in junior category differs after modern dance trainings compared to rhythmic gymnasts who do not receive modern dance trainings. The gymnasts consisted of 10-member Study Group and 10-member Control Group. The Study Group and Control Group were divided into random groups. The purpose was to determine whether modern dance training affected performance results and to determine whether there were statistically significant differences between rhythmic gymnasts who received and whop did not receive modern dance training.

According to the data that were obtained in the study, a significant difference was detected between the "D" scores of the Study Group (who received modern dance training), and the Control Group (who did not receive modern dance training) $(\mathrm{p}<0.05)$. The D score (difficulty elements) consist of the movements which an athlete can perform with a high degree of aesthetic and technical skill. The difficulty elements consist of 4 components, which are BD (Body Difficulty), S (dance steps), R (dynamic elements with rotation) and AD (Device Difficulty). There are no lines in showing the difficulties, and athletes can do these challenges anywhere in their series. Body Difficulty (BD) elements consist of jumps, balances and rotations (turns). Dance Steps (S) are performed with tempo, rhythm, character and pitch of the music that are not less than 8 seconds. The combinations include step forms 
(running, jumping, leaps), movements and turns in which the body moves in different directions at different levels. Several BD and R can be applied during dance steps. Dynamic elements with rotation $(\mathrm{R})$ can be performed by all or part of the body rotating around itself or around an axis. Each rotation can be used in a series maximum once; and repeating any of these in another $\mathrm{R}$ is not considered valid.

According to the data that were obtained after 10 days of training in the study, a significant difference was detected between the "E" score of the Study Group (who received modern dance training), and the Control Group (who did not receive modern dance training) ( $\mathrm{p}<$ 0.05). The E score (application of elements) refers to the perfect aesthetics and technique of the elements shown. Gymnasts should perform all the elements in the series by using a high degree artistic use. The E score is determined only by how the elements are performed, regardless of the difficulty degree. Every composition must have a point and the gymnast must convey it from the beginning to the end of the series. The character of music and the main idea must be combined in line with the body movements. The beauty and grace of the force that is used in movements, the diversity of them, the dominance of the gymnast over the whole area and the use of the whole body, including facial expressions, are the principles of the E score.

According to the data that were obtained in the study, a significant difference was detected between the "T" score of the Study Group (who received modern dance training) and the Control Group (who did not receive modern dance training) as a result of 10 weeks of training $(\mathrm{p}<0.05)$. The $\mathrm{T}$ score refers to the total result taken after combining $\mathrm{D}$ and $\mathrm{E}$ points. The final score of the series is determined by adding $\mathrm{D}$ and $\mathrm{E}$ points, and the ranking of the gymnasts is based on this score.

Dance has taken its place between sports and art because of involving a sense of rhythm, aesthetics, technical requirements and the need for good training (Baldari \& Guidetti, 2001). The athletes who learn modern dance techniques can realize that the limits of using their bodies are much wider, and use it in rhythmic gymnastics series. Various studies in this respect (Crotts et al., 1996), (Golomer et al., 1997), (Mouchnino et al., 1992) argued that dancers have better balance controls than the control groups that do not receive dance training. Postural coordination allows increased balance performance by increasing activities like dance, gymnastics or judo (Gautier et al., 2008), (Golomer et al., 1999). One of the advantages that is provided by modern dance for the rhythmic gymnastics athlete is the transmission of the main emotion to be emphasized in dance by turning the posture in dance steps used into a more natural position. In this way, the athlete who works in a natural position has the opportunity of developing by adding the improvisation experience s/he has not previously performed. Modern dance provides the setting for new discoveries (Narl1, 2014). Different learning methods positively affect the athlete's learning habits, develop new thoughts for better control, management and orientation of the athlete and casts light upon his/her horizons.

According to these findings, it was determined that modern dance training had an effect on the results of the competition. As a result, it was also determined that there was a statistically 
positive relation between the rhythmic gymnasts who received modern dance training and the rhythmic gymnasts who did not. It was also found that the performance success results of the rhythmic gymnasts who were trained in modern dance increased. For this reason, it is considered that the inclusion of modern dance training in rhythmic gymnastics training will positively affect the achievements of athletes.

\section{References}

Agopyan, A. (1993). The Effect of Morphological and Motoric Properties on Rhythmic Sports Gymnastics (Master Thesis, Institute of Health Sciences, Marmara University).

Ayça, B., Agopyan, A., Şener, A., Oba, R., \& Pastırmac1, G. (2008). Evaluation of gamma-glutamyl transferase changing in urine related to the training load in the rhythmic gymnasts competitors aged 7-10. Biol Sport, 25, 233-44.

Baldari, C., \& Guidetti, L. (2001). Vo2max, ventilatory and anaerobic thresholds in rhythmic gymnasts and young female dancers. J Sports Med Phys Fitness, 41, 177-182.

Crotts, D., Thompson, B., Nahom, M., Ryan, S., \& Newton, R. A. (1996). Balance abilites of professional dancers on select balance tests. The Journal of Orthopaedic and Sports Physical, 23(1), 12-17. Retrieved from https://www.jospt.org/doi/10.2519/jospt.1996.23.1.12

Galioğlu, A. (2007). Latin dance courses in Izmir and sexuality in dance practice (Master Thesis, Dokuz Eylül University, Institute of Fine Arts, Izmir).

Gautier, G., Thouvarecq, R., \& Vuillerme, N. (2008). Postural control and perceptive configuration: influence of expertise in gymnastics. Gait \& Posture, 28(1), 46-51. https://doi.org/10.1016/j.gaitpost.2007.09.007

Golomer, E., Cremieux, J., Dupui, P., Isableu, B., \& Ohlmann, T. (1999). Visual contribution to self-induced body sway frequencies and visual perception of male professional dancers. Neuroscience Letters, 267(3), 189-192. https://doi.org/10.1016/S0304-3940(99)00356-0

Golomer, E., Dupui, P., \& Monod, H. (1997). Sex-linked differences in equilibrum reactions among addescents performing complex sensorimotor tasks. Journal of Physiology-Paris, 91(2), 49-55. https://doi.org/10.1016/S0928-4257(97)88937-1

Golomer, E., Dupui, P., \& Monod, H. (1997). The effects of maturation on self-induced dynamic body sway frequencies of girls performing acrobatisc or classical dance. Europen Journal of Appiled Physiology and Accupational Physiology, 76(2), 140-144. https://doi.org/ $10.1007 / \mathrm{s} 004210050226$

Koç, H. (1996). Administrative and Financial Structure of Gymnastics Federation, Athletes, Coaches, Referees, Examination of Materials. Example of Bolu Province (Master Thesis, Institute of Health Sciences, Marmara University, Istanbul).

Lin, C. M. (2005). Perception Of Dance Instructors Regarding General Dance Education Curricula In Taiwan (UMI No. 3188198). The University of South Dakota, USA.

Mathews, D. K. (1978). Measurement in Physical Education. W. B. Philadelphia: Saunders. 


\section{Macrothink}

Mihçığlu, E. (2000). Transition from Classical Ballet to Modern Dance and Development of Modern Dance. Post Graduate Art Work Study Report, Hacettepe University, Ankara.

Morpa Sports Encyclopedia. (1997). Morpa Kültür Yayınları Ltd. Sti. Istanbul.

Mouchnino, L., Aurenty, R., Massion, J., \& Pedotti, A. (1992). Coordination between equilibrum and head-trunk orientation during a leg movement: a new strategy built up by training. Journal of Neurophysiology, 67, 1587-1598. https://doi.org/10.1152/jn.1992. 67.6.1587

Narl1, A. (2014). Contribution of modern dance training process to classical ballet dancer training, Hacettepe University, Ankara.

\section{Copyright Disclaimer}

Copyright for this article is retained by the author(s), with first publication rights granted to the journal.

This is an open-access article distributed under the terms and conditions of the Creative Commons Attribution license (http://creativecommons.org/licenses/by/3.0/). 